\section{Drying/encapsulation of red wine to produce ingredients for healthy foods}

\author{
Izmari Jasel Alvarez Gaona, ${ }^{1,2}$ \\ Diego Rocha-Parra,, \\ Maria C. Zamora, ${ }^{1,2}$ Jorge Chirife ${ }^{1}$ \\ ${ }^{1}$ Faculty of Engineering and \\ Agricultural Sciences, Pontifical \\ Catholic University Argentina, C.A.B.A. \\ ${ }^{2}$ National Council of Scientific and \\ Technical Research (CONICET \\ acronym in spanish), C.A.B.A., \\ Argentina
}

\begin{abstract}
Epidemiological evidence indicates that moderate consumption of red wine reduces the incidence of coronary disease, atherosclerosis, and platelet aggregation. Wine is very rich in antioxidant compounds because of their phenolic components. However, many people for ethnic, social or religious reasons do not consume wine. Drying/encapsulation of red wine in the presence of adequate carbohydrates leads to water and more than $99 \%$ of alcohol removal; a glassy amorphous microstructure is obtained in which the wine's phenolic compounds are entrapped. The resulting product is a free flowing powder which could be used for the polyphenol enrichment of healthy foods and/or drink powders, as well as in the pharmaceutical industry. The wine industry may take advantage of the dried/encapsulated red wine using as a raw material red wines which have little commercial value for different reasons; i.e. poor quality due to raw material, unfavourable climatic conditions, or wines that suffered some alteration during the wine making process. Dry encapsulated wine may be a new alternative to red wines that cannot be sold as such for different reasons, and open new opportunities to diversify wine products.
\end{abstract}

\section{Introduction}

\section{Health properties of red wine}

Wines are rich in compounds as flavonoids (catechins, flavonols, and anthocyanins) which are responsible for health benefits. Red wine, as a consequence of its polyphenolic content can be considered a useful raw material for making a number of different healthy food and drink products. ${ }^{1,2}$
The regular and moderate wine consumption is one of the most evoked facts for explaining the low incidence of cardiovascular events in France (the so-called French paradox) compared with other industrialized countries. ${ }^{3-5}$ It has been suggested that the phenolic compounds highly abundant in red wine might be responsible for this improvement in health in the French population. Small daily intakes of wine can reduce the risk of cardiovascular disease (CVD), this benefit is ascribed to the antioxidants properties of the phenolic compounds..$^{6-9}$

Red wine polyphenols have vasorelaxing effects, which are associated with lower blood pressure. ${ }^{10}$ Red wine, dealcoholized red wine, and grape juice consumption have lowered blood pressure in patients with coronary artery disease or hypertension. ${ }^{11-14}$ The data reported suggest that polyphenols, rather than alcohol, are responsible for the health benefits. The balance between alcohol and polyphenols in a wine may be critical in determining its antioxidant potential. ${ }^{15}$ It is known that alcohol has pro-oxidant effects and studies performed with dealcoholized wine, grapes, and grape seed extract have shown strong antioxidant effects, indicating that the polyphenol content contributes critically to the antioxidant abilities of wine. ${ }^{16-24}$

There are, however, some drawbacks associated with the ingestion of alcohol present in the wine: i) consumption must be moderate (i.e., one to two glasses per day) in order to avoid alcohol-related diseases, and ii) ethnical, social, or religious reasons may prevent certain sectors of the population from consuming wine. Since red wine polyphenols in general are known to exhibit very high-biological activity ${ }^{25-27}$ interest has grown in the possibility of producing nonalcoholic wine extracts containing red wine polyphenols. However, these functional ingredients bring additional challenges in terms of the stability of their bioactive compounds during storage and processing. The development of these products may be an important research area for the food and pharmaceutical sectors (i.e. nutraceuticals). It has been shown that the removal of ethanol from red wine does not decrease its beneficial health properties, namely its antioxidant effects and protection against CVD. ${ }^{28,29}$ These findings provide new insights into the role of dietary components such as red wine polyphenols in promoting cardiovascular health, particularly in blood pressure regulation.

\section{Red wine dehydration/encapsulation}

Freeze-drying has been proved to be the most suitable method for drying thermosen-
Correspondence: Izmari Jasel Alvarez Gaona, Facultad de Ingenieria y Ciencias Agrarias, Pontificia Universidad Catolica Argentina, Av. Alicia Moreau de Justo 1516-1560, C1107AFF CABA, Argentina.

Tel.: (54 11) 43490200.

E-mail: izmarialvarez@uca.edu.ar

Key words: Red wine polyphenols, freeze drying, spray drying, encapsulation, maltodextrin.

Acknowledgments: Authors acknowledge financial support from Facultad de Ingeniería y Ciencias Agrarias, Pontificia Universidad Católica Argentina.

Contributions: IJAG, DRP: compilation and ordering of the literature data; MCZ, JC: supervision and selection of the results and did the final editing.

Conflict of interest: the authors declare no potential conflict of interest.

Funding: authors acknowledge financial support from Faculty of Engineering and Agrarian Sciences, Pontifical Catholic University Argentina, C.A.B.A.

Received for publication: 6 October 2017 Revision received: 12 December 2017.

Accepted for publication: 12 December 2017.

This work is licensed under a Creative Commons Attribution NonCommercial 4.0 License (CC BY-NC 4.0).

(C) Copyright I.J.A. Gaona et al., 2017

Licensee PAGEPress, Italy

Wine Studies 2017; 6:7126

doi:10.4081/ws.2017.7126

sitive substances, minimizing thermal degradation reactions. It has also been used to encapsulate delicate biomaterials in amorphous carbohydrate microstructure matrices..$^{30,31}$ Thus, drying/encapsulation of red wine by freeze-drying could be used to protect the polyphenols by preventing their oxidation and making handling easier. Munin and Edwards-Lévy ${ }^{32}$ noted that although polyphenols are compounds possessing interesting properties for use in medicine, they lack of long term stability since are usually very sensitive to light and heat, encapsulation appears to be a promising approach to gain stability. Maltodextrin and arabic gum, are among the wall materials which have been used in fruit juice encapsulation using spray drying or freeze drying techniques. ${ }^{33,34}$ Other authors also indicated that maltodextrin is the most common carbohydrate matrix used for encapsulation stability, i.e., protecting against undesirable physical (stickiness and collapse) 
and/or chemical changes, such as oxidation. $^{30,35}$

Wine dehydration removes simultaneously water and almost all alcohol leaving a concentrate of the wine dry extract containing its polyphenols. However, wine dehydration is not a simple task. In a study of the health effects of only wine polyphenols without the influence of alcohol, Van Galde et al. ${ }^{36}$ used the technique of freeze-drying to remove alcohol and water, but he did not utilize any encapsulation material.

Sanchez et al. ${ }^{37}$ reported that this procedure leads to an amorphous rubbery mass of the wine dry extract which was very difficult to handle. However, when $20 \%$ (w/w) of maltodextrin $\mathrm{DE}_{10}(\mathrm{MD})$ was added to wine before freeze-drying they obtained an amorphous microstructure of glassy appearance which was easily milled into a freeflowing powder resembling the characteristic red wine's colour (wine powder from now on). Figure 1 compares the aspect of plain freeze dried red wine (A), red wine freeze-dried with $20 \%$ maltodextrin (B), and wine freeze-dried with a mixture of $9 \%$ maltodextrin and arabic gum (C). Sanchez et al. ${ }^{37}$ indicated that the physical stability of wine powder was related to its glass transition temperature (Tg). Freeze-dried carbohydrates/proteins may exist in an amorphous state with time dependent physical properties, which affect their storage stability. ${ }^{30,31}$ Amorphous materials undergo a change from a very viscous glass to a rubber at the glass transition temperature which often results in structural alterations such as stickiness and collapse. Encapsulation of the wine's dry extract in an amorphous glassy matrix of MD was possible because of the high $\mathrm{Tg}$ of MD as compared to the Tg values of various main constituents of wine's dry extract, namely, glycerol, tartaric, malic and citric acids, fructose and glucose. $\mathrm{Tg}$ for anhydrous $\mathrm{MD} \mathrm{DE}_{10}$ is $160^{\circ} \mathrm{C},{ }^{38}$ while values of anhydrous glucose, tartaric acid, fructose, malic acid, and glycerol are much lower, being 30, 18, 8, -21 , and $-85{ }^{\circ} \mathrm{C}$ respectively. ${ }^{30,39-44}$ Glycerol, the wine constituent having lowest $\operatorname{Tg}\left(-85^{\circ} \mathrm{C}\right)$ is by far, the main component of the red wine dry extract. This is in agreement with the observation of Sanchez et al. ${ }^{37}$ indicating the presence of an amorphous rubbery mass after freeze-drying of red wine without MD addition. Sanchez et al. ${ }^{37}$ measured the glass transition temperature of a sample of freeze-dried wine (without MD addition) and the Tg of this plastic rubbery material was found to be, $\mathrm{Tg}=-58.0^{\circ} \mathrm{C}$, (at $9.2 \%$ moisture content) and the addition of MD (20\%) before freeze drying resulted in a much higher glass transition temperature of $40.8^{\circ} \mathrm{C}$. Sanchez et

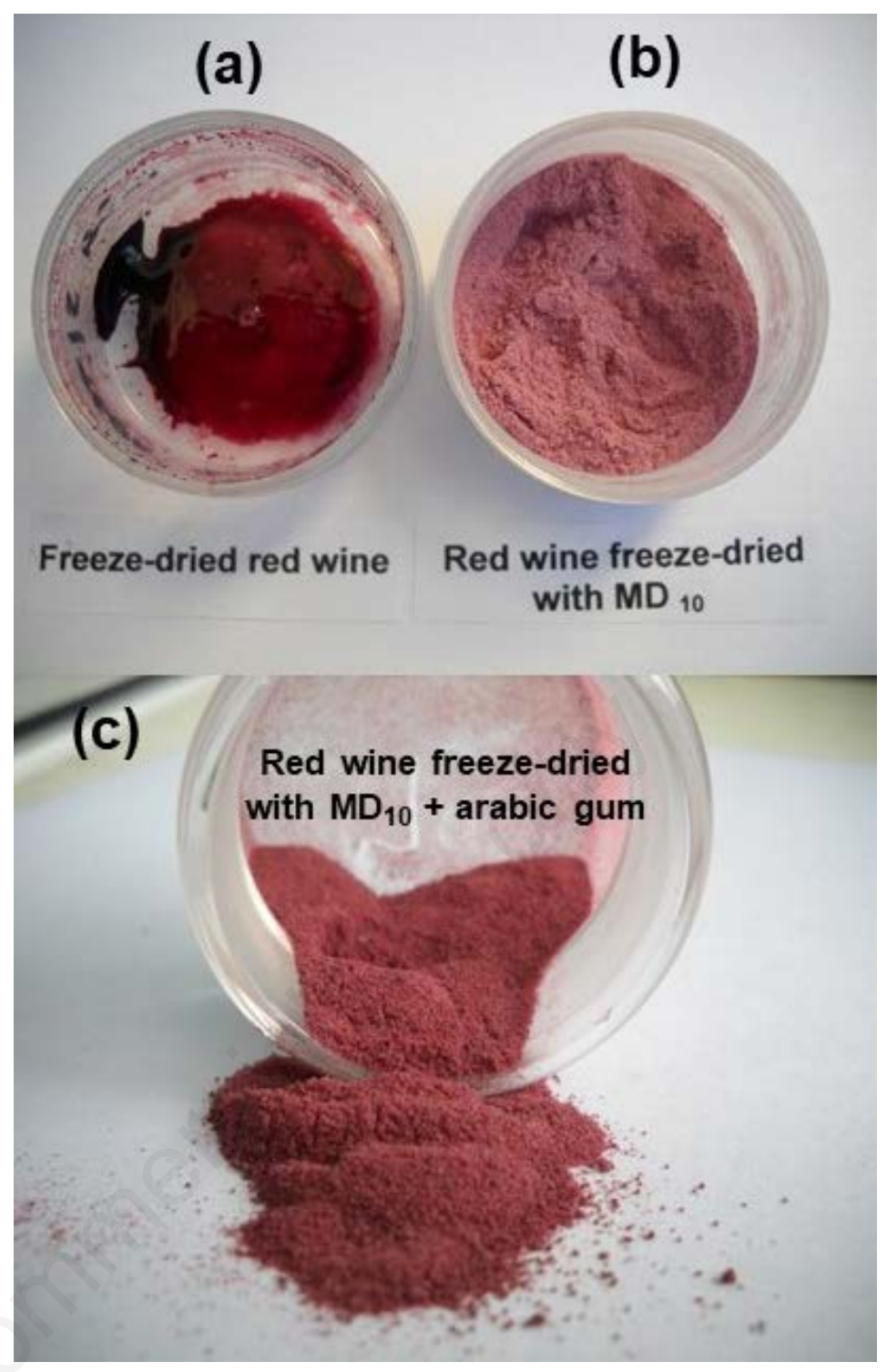

Figure 1. A) Freeze dried red wine; B) Freeze dried using maltodextrin (20\%) as encapsulant; C) Freeze dried wine using a mixture of maltodextrin + arabic gum (9\%) as encapsulants.

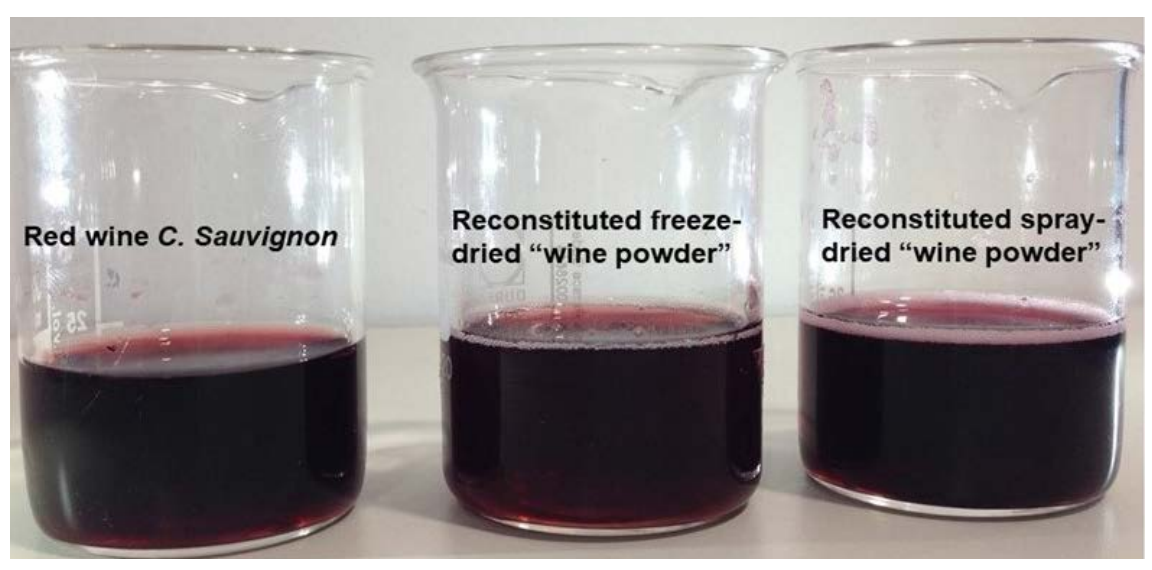

Figure 2. Comparison of visual colour of original red wine with reconstituted freeze-dried wine powder (encapsulant were MD + arabic gum) and reconstituted spray-dried wine powder (encapsulant was MD). 
$a l .{ }^{37}$ also reported that the retention of total polyphenol content in the powder after freeze-drying amounted to $97.8 \%$. Due to its low water activity $\left(\mathrm{a}_{\mathrm{w}}\right.$ below 0.25$)$ this wine powder was microbiologically stable at room temperature.

Figure 2 compares the visual colour of original red wine with that of reconstituted freeze dried wine powder (encapsulated with maltodextrin + arabic gum) and reconstituted spray dried wine powder (encapsulated with maltodextrin). This is not a quantitative colour comparison of the different wine samples; it only intends to provide the reader with a qualitative picture of the colour of dehydrated wines after reconstitution. The similarity of colours (Figure 2) is an advantage for developing healthy foods that do not have alcohol but contain wine polyphenols and retain the characteristic red colour of wine. Alvarez et al. ${ }^{45}$ measured the chromatic characteristics (absorbance at $420 \mathrm{~nm}, 520 \mathrm{~nm}$ and $620 \mathrm{~nm}$ ) of reconstituted red wine which has been spray dried at different temperatures $(135,145,155$ and $\left.175^{\circ} \mathrm{C}\right)$.

The wine powder developed by Sanchez et al. ${ }^{37}$ contained 3.7 times the concentration of total polyphenols present in red wine while containing less than $1 \%$ of ethanol. This increased the concentration of total polyphenols in the wine powder resulted from the balance between water and alcohol elimination and MD incorporation.

\section{Stability of phenolic compounds in stored freeze dried encapsulated red wine}

Galmarini et al.$^{46}$ studied the stability of several individual phenolic compounds of red wine encapsulated by freeze drying following 20\% (w/w) addition of maltodextrin $\mathrm{DE}_{10}$ to red wine (Cabernet sauvignon). The resulting powder, having a water activity $\left(\mathrm{a}_{\mathrm{w}}\right)$ of 0.053 and 0.330 was stored at 28 and $38^{\circ} \mathrm{C}$ and the content of ten different phenolic compounds was determined by high performance liquid chromatography (HPLC). Caftaric acid, quercetin-3-glucoside, caffeic acid, gallic acid and resveratrol contents in the wine powder stored at 28 and $38^{\circ} \mathrm{C}$, remained almost constant during 70 days of storage. Epicatechin gallate, catechin, malvidin-3-glucoside and epicatechin had small losses (about 15-25\%) during storage. Galmarini et al. ${ }^{46}$ also compared the stability of malvidin-3-glucoside and total anthocyanins in regular liquid wine $\left(\right.$ at $20^{\circ} \mathrm{C}$ ) and in the dry matrix of their wine powder (at $28^{\circ} \mathrm{C}$ ). The much higher stability of anthocyanins in wine powder, as compared to regular red wine, was attributed to the limited molecular mobility and diffusion rates associated with the low moisture content of wine powder. ${ }^{47}$

They also reported a moderate decrease of antioxidant activity, as determined by free radical scavenging capacity of the $\mathrm{DPPH}^{\cdot}$ and ferric reducing antioxidant power (FRAP) during storage. This decrease was more remarkable at higher temperature $\left(38^{\circ} \mathrm{C}\right)$ and $\mathrm{a}_{\mathrm{w}}(0.33)$ studied. These authors suggested their results would allow the feasibility of using this wine pow$d e r$ as a healthy ingredient in alcohol-free powder drinks.

Rocha-Parra et al. ${ }^{2}$ freeze dried a blend of red wine with $9 \%(\mathrm{w} / \mathrm{w})$ of a mixture of maltodextrin and arabic gum and obtained a wine powder having a polyphenols concentration 7.1 times higher than liquid red wine. The total concentration of encapsulating agents used by Rocha Parra et al. ${ }^{2}$ was considerably less than previously used by Sanchez et al..$^{37}$ and Galmarini et al ${ }^{46}$ which resulted in a powder with increasing concentration of wine polyphenols and also improved sensory profile (Rocha-Parra et al.). ${ }^{48}$ This comparison of polyphenols concentrations between wine liquid and wine powder is somewhat arbitrary. The objective is to calculate the amount of wine powder that must be added to a healthy powdered drink to have a certain amount of polyphenols; for example the polyphenols found in a glass of red wine. On this line, Rocha Parra et al. ${ }^{49}$ developed a fortified drink powder from wine powder and noted that $400 \mathrm{~mL}$ of this reconstituted healthy beverage contains about the same amount of wine polyphenols as a glass (about 100 $\mathrm{mL}$ ) of liquid red wine.

Rocha-Parra et $a .^{2}$ followed the behaviour of several phenolics in their freeze dried matrix composed of MD and arabic gum and found that concentration of gallic acid, catechin, epicatechin, caffeic acid and resveratrol remained approximately constant throughout 145 days storage at $\mathrm{a}_{\mathrm{w}} 0.11$ and $38^{\circ} \mathrm{C}$. On the contrary, malvidin3-glucoside showed an important initial decrease followed by a slower one. Catechin and epicatechin exhibited an initial decrease but then remained constant up to the end of storage (145 days). At a higher $\mathrm{a}_{\mathrm{w}}=0.33$, losses of caffeic acid and resveratrol were 29 and $31 \%$ respectively. Malvidin-3-glucoside showed the largest decrease amounting to about $70 \%$ of its initial value after storage at $38^{\circ} \mathrm{C}$ and $\mathrm{a}_{\mathrm{w}}=0.33$. These authors highlighted that the decrease in malvidin-3-glucoside content was associated (as expected) with the decrease in redness of wine powder.

The $\%$ retention of different phenolics in encapsulated and non-encapsulated freeze-dried wine after 145 days storage at $38^{\circ} \mathrm{C}$ (at two different water activities 0.11 and 0.33) is shown in Figure 3 from RochaParra. ${ }^{50}$ Encapsulation leads to higher retention after storage indicating that encapsulation afforded better protection of phenolic compounds. In wine powder without encapsulation materials the retention of malvidin3 -glucoside and resveratrol after storage is null. On the contrary, gallic acid shows a $100 \%$ retention at all conditions examined.

Overall, the stability behaviour of selected phenolics in the wine powder encapsulated with a mixture of maltodextrin and arabic gum ${ }^{2}$ was similar to that reported by Galmarini et al. ${ }^{46}$ for same phenolics in red wine freeze-dried encapsulated with $20 \%$ of maltodextrin.

Rocha-Parra et $a .^{2}$ also measured antioxidant capacity of wine powder determined with chromogen radical $\mathrm{DPPH}^{*}$ and antioxidant capacity determined by $\beta$ Carotene/Linoleic acid assay, and reported

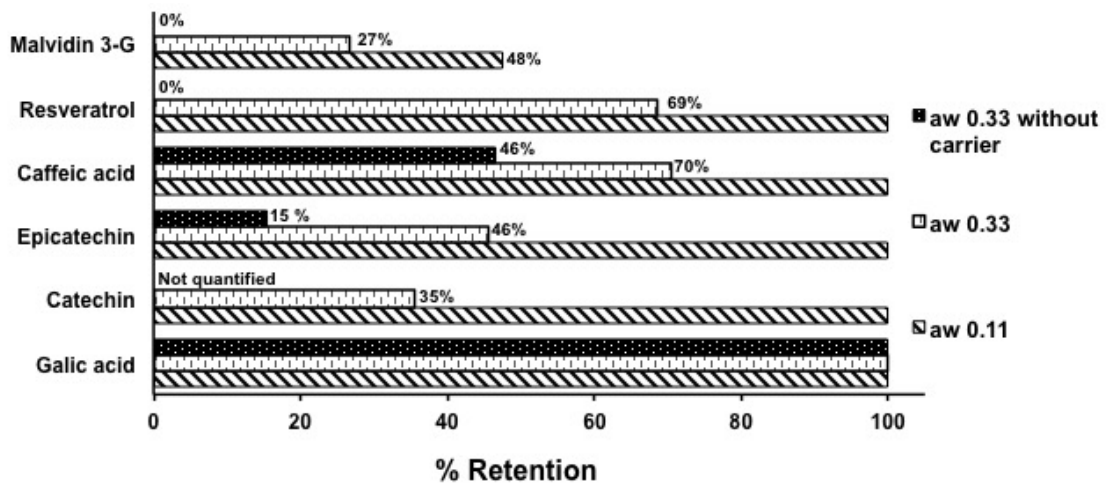

Figure 3. Retention of wine phenolics in freeze-dried wine powder after 145 days storage at $38^{\circ} \mathrm{C}$ and 0.11 and 0.33 water activity (adapted with permission from data of RochaParra, 2016)..$^{50}$ 
it remained approximately constant during storage. This behaviour was attributed to many factors which influence hydrolysis, oxidation and condensation reactions which take place during wine storage. They indicated that the lack of correlation between the loss of some phenolics and antioxidant capacity has been also reported by others authors in different food systems. For example, Kallithraka et al. ${ }^{51}$ found that although content of most phenolics in stored white bottled wine decreased with time, while the antioxidant activity increased; and this was attributed to reactions between oxidised phenolics which may produce formation of new antioxidants.

Both, Galmarini et al. ${ }^{46}$ and RochaParra et $a l .^{2}$ noted that increasing the water activity of wine powder strongly affected the retention of total anthocyanins and malvidin-3-glucoside and stressed the importance of water activity as a control parameter for stability during storage of wine powder. It was concluded that freeze drying encapsulation of red wine polyphenols in a suitable matrix offers an effective and practical method for the preparation of nonalcoholic and low moisture formulations (wine powder) of wine phenolics.

\section{Spray drying encapsulation of red wine}

Spray drying may also be employed successfully in the microencapsulation of active compounds within a suitable matrix at a lower cost than freeze drying. For these reasons spray-drying is commonly used to preserve heat-sensitive bioactive substances via encapsulation to produce powdered food ingredients or nutraceutical products. $^{52,53}$

Although several studies of fruit juice encapsulation have shown spray drying to have a positive effect on the stability of fruit polyphenols information about its impact on wine polyphenols was not available until very recently. ${ }^{54-59}$ Wilkowska et al. ${ }^{60}$ spray dried black chokeberry (Aronia melanocarpa) juice and wine using maltodextrin, a mixture of maltodextrin with arabic gum and hydroxypropyl- $\beta$-cyclodextrin as coating materials. They followed degradation kinetics of polyphenols and antioxidant stability in microencapsulated juice and wine preparations from chokeberry over 12 months under storage at 8 and $25^{\circ} \mathrm{C}$. Wilkowska et $a l .{ }^{60}$ reported that the type of encapsulation material proved to have a significant effect on the storage stability of polyphenol microencapsulates. Microcapsules of maltodextrin showed a loss of $25 \%$ in total anthocyanins after 12 months storage at $25^{\circ} \mathrm{C}$. The effect of mois- ture content (or aw) on anthocyanins stability during storage was not reported. Wilkowska et al. ${ }^{61}$ also spray dried different fruit wines (chokeberry, blackcurrant and blueberry) using hydroxypropyl- $\beta$ cyclodextrin and inulin as encapsulation materials and followed the structural, physicochemical, and biological properties of the spray-dried wine powders over 12 months of storage in darkness under refrigeration $\left(8^{\circ} \mathrm{C}\right)$. It was also reported that spray drying of fruit wine at inlet temperature of $140^{\circ} \mathrm{C}$ lead to a powder with less than $1 \%$ ethanol content.

Alvarez Gaona et al.$^{45}$ published on the feasibility of spray drying to encapsulate red wine in a maltodextrin matrix. After using a mixture of red wine (Cabernet sauvignon) with $13.5 \%(\mathrm{w} / \mathrm{w})$ maltodextrin $\mathrm{DE}_{10}$ the encapsulated wine contained a 5 times higher concentration of total anthocyanins than liquid wine. They noted that spray-drying of red wine is difficult due to stickiness issues caused by the presence of glycerol, intrinsic sugars and organic acids with low glass transition temperature. However, the addition of $\mathrm{MD} \mathrm{DE}_{10}$ to the mixture before spray-drying was an effective approach to tackle this issue. The outlet air temperatures used by Alvarez Gaona et $a l .^{45}$ were in the range $75-79^{\circ} \mathrm{C}$ and in all drying batches a free-flowing powder having $\mathrm{a}_{\mathrm{w}}$ below 0.20 was obtained. The retention of Total Monomeric Anthocyanins (TMA) in the wine powder was found to be above $83 \%$ depending on the inlet air temperature $\left(135\right.$ to $\left.170^{\circ} \mathrm{C}\right)$.

Alvarez Gaona et al..$^{45}$ Rocha-Parra et $a l .^{2}$ determined a water sorption isotherm (for a reduced range of relative humidities) of their spray dried and freeze-dried encapsulated red wine and noted that above $43 \%$ $\mathrm{RH}$ the structure of wine powder collapsed and released a typical red wine colour. After an equilibrium time of some weeks, powder caking was observed at $\mathrm{a}_{\mathrm{w}}=0.43$ but not at $\mathrm{a}_{\mathrm{w}}=0.33$ and below. This behaviour may be explained considering that physical changes in an amorphous matrix are time dependent being a function of (T-Tg), where $\mathrm{T}$ is the storage temperature and $\mathrm{Tg}$ is the glass transition temperature. ${ }^{62}$ Rocha-Parra et al. ${ }^{2}$ measured the glass transition temperature of their wine powder at $\mathrm{a}_{\mathrm{w}}=0.33$ and found $\mathrm{a}$ value of $51^{\circ} \mathrm{C}$. Since this value is higher than storage temperature $\left(38^{\circ} \mathrm{C}\right)$, the absence of caking at $\mathrm{a}_{\mathrm{w}}=0.33$ and below may be attributed to the presence of a glassy state. ${ }^{45}$

Alvarez Gaona et $a l .{ }^{45}$ explained the high TMA retention as follows: drying of droplets (wine containing the dissolved MD) can be divided into two different stages known as the constant rate period and the falling rate period. In the first stage, the droplet diameter decreases due to water evaporation, droplet evaporation rate is nearly constant and the droplet surface temperature $\left(T_{s}\right)$ is also constant and equal to the wet bulb temperature $\left(\mathrm{T}_{\mathrm{wb}}\right)$. An important fraction of the available moisture in the droplet may be removed during the period of constant rate, thus protecting anthocyanins from degradation because $T_{s}=T_{w b}$. As more moisture is removed from the droplet, the amount of maltodextrin dissolved in the liquid increases its concentration and forms a shell (crust) at the droplet surface. The beginning of crust formation determines that evaporation rate is now dependent on the rate of water vapour diffusion through the dried surface shell. Evaporative cooling is no longer sufficient to maintain $\mathrm{T}_{\mathrm{s}}=\mathrm{T}_{\mathrm{wb}}$ causing a gradual increase in $\mathrm{T}_{s}$. Although the particle will begin to heat it is at the coolest part of the

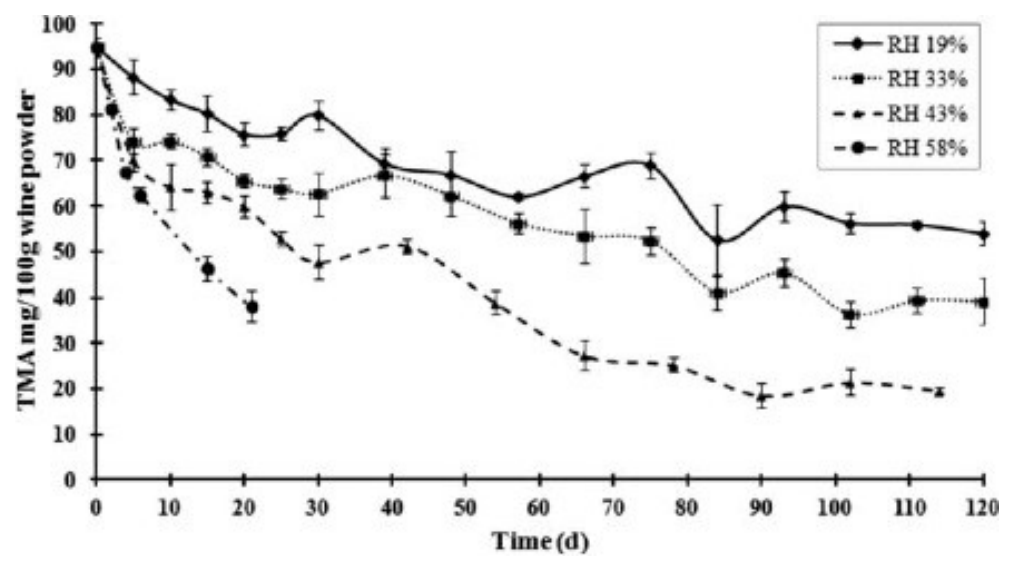

Figure 4. Stability of total monomeric anthocyanins in spray dried encapsulated red wine stored at $38^{\circ} \mathrm{C}$ and increasing relative humidities. Reproduced with permission (@2017 Wiley Periodicals, Inc) from Alvarez Gaona et al..$^{45}$ 
spray dryer, where the drying air is at or near the outlet temperature of the dryer. Thus, the particles are never heated above the outlet temperature of the dryer $\left(75-79^{\circ} \mathrm{C}\right.$ in their experiments). Alvarez Gaona et al. ${ }^{45}$ stored their wine powder under various relative humidities, and total monomeric anthocyanins concentration was determined up to 120 days at $38^{\circ} \mathrm{C}$. The results are shown in Figure 4 as reported by RochaParra et al. ${ }^{2}$ for freeze-dried encapsulated red wine. When $\mathrm{RH} \%$ is increased anthocyanins decrease steadily during storage enhancing the losses. The importance of $\mathrm{a}_{\mathrm{w}}$ (or $\mathrm{RH} \%$ ) as a key control parameter for anthocyanins stability during storage of wine powder was stressed by both authors.

Alvarez Gaona et al. ${ }^{45}$ noted that their spray dried encapsulated wine totally collapsed when exposed six days to $58 \% \mathrm{RH}$ and $38^{\circ} \mathrm{C}$ and further investigated this behaviour using wine model systems containing various non-volatile components of the dry extract, namely glycerol, organic acids, and monosaccharides. It was observed and compared that the structural alterations that occurred in spray dried wine model systems formulated with and without glycerol and stored at identical temperature, $\mathrm{RH} \%$, and time. Furthermore, the spray dried red wine and model system formulated with glycerol, experimented a noticeable radial shrinkage as a function of time when exposed at $58 \% \mathrm{RH}$ and $38^{\circ} \mathrm{C}$; however, this was not observed in the model system without glycerol. Alvarez et al. ${ }^{45}$ concluded that structural alterations of spray dried encapsulated wine were mainly due to glycerol (a main component of dry extract) because it has a very low glass transition temperature. It is to be noted that glycerol in wine is mainly formed as a by-product of glyceropyruvic fermentation by wine yeasts and its amount is influenced by several factors such as yeasts strain, fermentation temperature and addition of sulphur dioxide..$^{63}$

Very recently, Avellone et al. ${ }^{64}$ studied the spray drying of various Italian red wines. For this purpose, maltodextrin was dissolved in wine $(16.7 \%)$ and the drying was performed at relatively low temperatures, $105^{\circ} \mathrm{C}$ inlet air temperature and $65^{\circ} \mathrm{C}$ outlet air temperature. Neither the final moisture content or water activity of the wine powder obtained under mentioned drying temperatures were reported. Therefore, no predictions can be made about the physical/chemical storage stability of their wine powder. The main purpose of Avellano et al. ${ }^{64}$ was to evaluate if spray drying affects the important components of aroma, phenolic, and anthocyanin derived compounds. They found a marked reduction of active odour compounds in the encapsulated wines; a two-fold reduction of volatiles was reported. The behaviour is in agreement with earlier studies on volatile retention during spray drying of maltodextrin solutions containing added organic volatiles. ${ }^{65-67}$ Conversely, a qualitative screening of the polyphenolic fraction was carried out by means of UHPLC-HESIMSA analysis and reported a very high retention of polyphenols.

Avellano et al. ${ }^{64}$ suggested that their wine powder can be reconstituted as normal wine adding a hydroalcoholic solution. However, it's doubtful that this product can be denominated as normal wine since it will contain a considerable amount of dissolved maltodextrin (added before spray drying).

\section{Development of a healthy drink beverage using wine powder}

Rocha-Parra et al. ${ }^{48}$ developed a fruit flavoured powder beverage, having the same polyphenols of red wine but without the alcohol content. The wine powder which constituted the base of this healthy beverage was obtained by freeze drying the wine using MD and arabic gum as encapsulating agents ( $9 \% \mathrm{w} / \mathrm{w}$ total amount). On the basis of preliminary observations, the new beverage was formulated according to two factors: the amount of wine powder and the level of non-caloric sweetener. Four formulations were selected following four combinations (for 1 litre of reconstituted drink powder): $35 \mathrm{~g}$ of wine powder $+4 \mathrm{~g}$ of commercial sweetener (the sample here called $35-4)$; $40 \mathrm{~g}$ of wine powder $+4 \mathrm{~g}$ of commercial sweetener (here called 40-4); $35 \mathrm{~g}$ of wine powder $+5 \mathrm{~g}$ of commercial sweetener (35-5) and 40g of wine powder $+5 \mathrm{~g}$ of commercial sweetener (40-5). All the formulations had the same concentration of raspberry aroma and thickener. Different methodologies were used to detect differences in acceptance between formulations. The participants (144) were asked to evaluate the four samples in different aspects: overall acceptance, emotional status, body/viscosi-

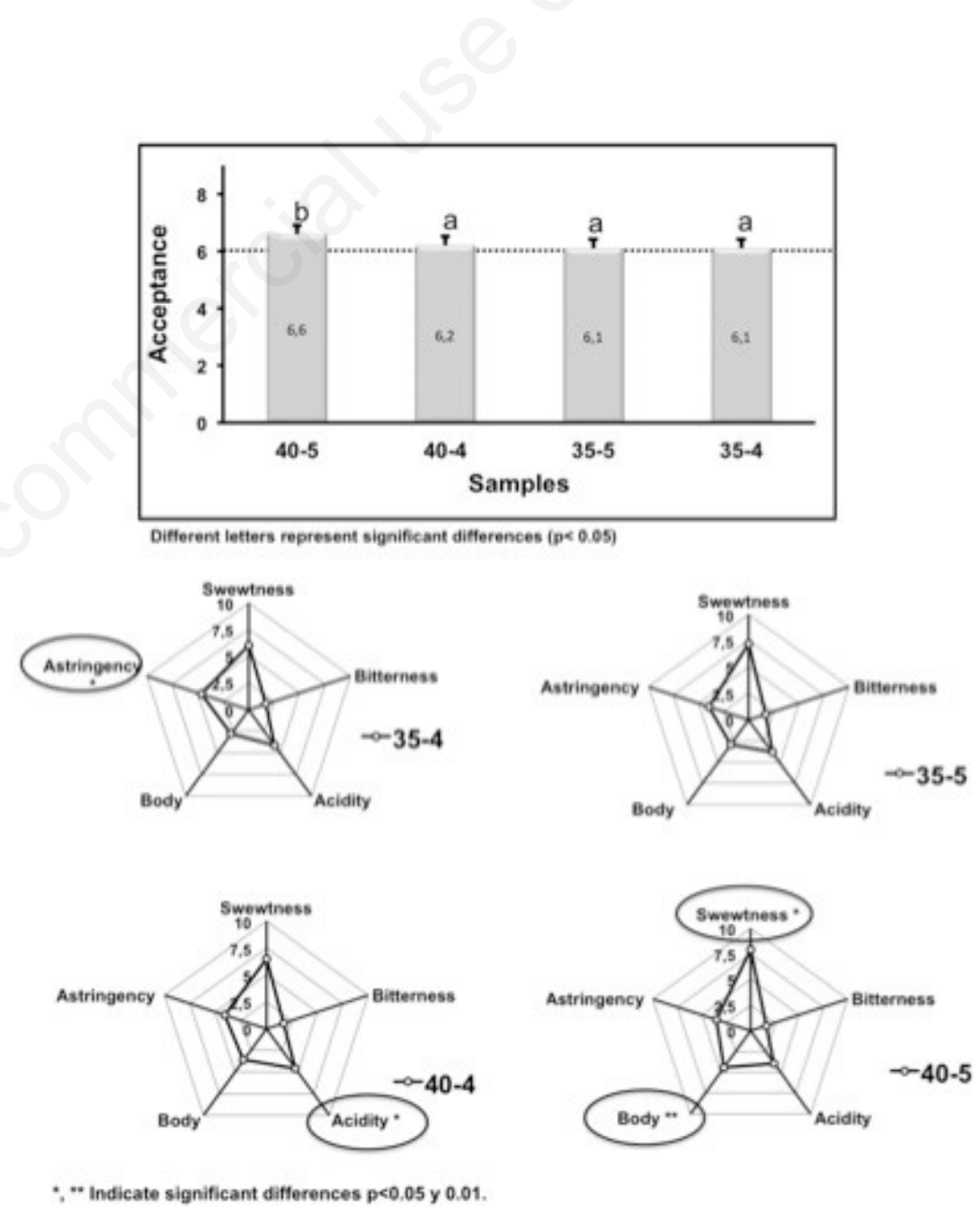

Figure 5. Results of the consumer test of a healthy drink powder elaborated from wine powder (adapted with permission from data of Rocha-Parra, 2016). ${ }^{50}$ 
ty, freshness, aroma, drinking and purchase intention, etc. Rocha-Parra ${ }^{48}$ found that most accepted sample was 40-5 with a score of $6.6 \pm 1.3$ as can be observed in Figure 5. The other samples were well valued taking into account that all were above 6 on a 9point category scale.

A quantitative descriptive analysis (QDA) was also carried out by a trained panel. According to the results of the panel it can be observed (Figure 5) that the attributes which showed differences among samples were sweetness, acidity, body, yeast, berry fruits, and astringent aftertaste. Body was the most relevant descriptor to explain variations among the four formulations, and sweetness highlighted the body perception. This effect was only observed when the samples with the highest amounts of wine powder (40-5 and 40-4) were compared. Therefore, this level of powder was necessary to induce the body enhancement. To the contrary, sample 35-4 was perceived as less sweet and with the highest astringent aftertaste. $^{50}$

\section{Conclusions}

Prospects for utilization of wine powder as a healthy ingredient in foods and drink powders.

The shelf-stable wine powder obtained via freeze drying or spray drying using suitable encapsulation materials might be useful to enhance some of the health-related advantages associated with red wine polyphenols, but avoiding the main disadvantage of wine, i.e., its alcohol content. The encapsulated wine powder may be used as nutraceutical for the pharmaceutical industry, and as an ingredient for healthy foods and powder beverages. This free flowing powder is readily dissolved in water, easy to handle, shelf-stable (due to of its low $\mathrm{a}_{\mathrm{w}}$ ) and could be integrated as an ingredient in different food systems. Precautions must be taken to maintain a low water activity to avoid undesirable structural alterations.

The wine industry may also take advantage of the of wine powder by using raw material which have little commercial value to the industry for different reasons, i.e. poor quality due to raw material, unfavourable climatic conditions or wines that suffered some alteration during the wine making process (i.e. aromatic defect, high volatile acidity). For this reason, dry encapsulated wine may be a new alternative to red wines that cannot be sold as such for different reasons, and may open new opportunities to diversify wine not just as an oenological product. It is hoped that this review will increase the interest of the scientific community to seek alternatives to the use of wine beyond oenology industry.

\section{References}

1. Di Giacomo G, Taglieri L. Production of red wine polyphenols as ingredient for the food and pharmaceutical industry. Int J Food Sci Nutr Eng 2012;2:125.

2. Rocha Parra DF, Lanari MC, Zamora $\mathrm{MC}$, Chirife J. Influence of storage conditions on phenolic compounds stability, antioxidant capacity and colour of freeze-dried encapsulated red wine. LWT-Food Sci Technol 2016;70:16270.

3. Soulat T, Philippe C, dit Sollier C, et al. Wine constituents inhibit thrombosis but not atherogenesis in C57BL/6 apolipoprotein E-deficient mice. Brit $\mathrm{J}$ Nutr 2006;96:290-8.

4. Nikfardjam Pour MS, Márk L, Avar P, et al. Polyphenols, anthocyanins, and trans-resveratrol in red wines from the Hungarian Villány region. Food Chem 2006;98:453-62.

5. Gorelik S, Ligumsky M, Kohen R., Kanner J. A novel function of red wine polyphenols in humans: prevention of absorption of cytotoxic lipid peroxidation products. FASEB J 2008;22:41-6.

6. Renaud S, de Lorgeril M. Wine, alcohol, platelets, and the French paradox for coronary heart disease. Lancet 1992;339:1523-6.

7. Mazza G, Francis FJ. Anthocyanins in grapes and grape products. Crit Rev Food Sci 1995;35:341-71.

8. Radovanovic B, Radovanovic A. Free radical scavenging activity and anthocyanin profile of Cabernet Sauvignon wines from the Balkan region. Molecules 2010;15:4213-26.

9. Diaz B, Gomes A, Freitas M, et al. Valuable polyphenolic antioxidants from wine vinasses. Food Bioprocess Tech 2012;5:2708-16.

10. Carollo C, Presti R, Caimi G. Wine, diet, and arterial hypertension. Angiology 2007;58:92-6.

11. Foppa M, Fuchs FD, Preissler L, et al. Red wine with the noon meal lowers post-meal blood pressure: A randomized trial in centrally obese, hypertensive patients. J Stud Alcohol 2002;63: 247-51.

12. Park YK, Kim JS, Kang MH. Concord grape juice supplementation reduces blood pressure in Korean hypertensive men: Double-blind, placebo controlled intervention trial. Biofactors 2004;
22:145-7.

13. Karatzi KN, Papamichael CM, Karatzis TG, et al. Red wine acutely induces favorable effects on wave reflections and central pressures in coronary artery disease patients. Am J Hypertens 2005; 18:1161-7.

14. Jimenez J, Serrano J, Tabernero M, et al. Effects of grape antioxidant dietary fiber in cardiovascular disease risk factors. Nutrition 2008;24:646-53.

15. van Golde PH, Sloots LM, Vermeulen WP, et al. The role of alcohol in the anti low density lipoprotein oxidation activity of red wine. Atherosclerosis 1999;147:365-70.

16. Young JF, Dragsted LO, Daneshvar B, et al. The effect of grape-skin extract on oxidative status. Br J Nutr 2000;84:50513.

17. Abu-Amsha Caccetta R, Burke V, Mori $\mathrm{TA}$, et al. Red wine polyphenols, in the absence of alcohol, reduce lipid peroxidative stress in smoking subjects. Free Radic Biol Med 2001;30:636-42.

18. Bagchi D, Bagchi M, Stohs S, et al. Cellular protection with proanthocyanidins derived from grape seeds. Ann NY Acad Sci 2002;957:260-70.

19. Durak I, Karaca L, Cimen MB, et al. Dried white grapes enhance blood antioxidant potential. Nutr Metab Cardiovasc Dis 2002;12:204-5.

20. Park YK, Park E, Kim JS, Kang MH. Daily grape juice consumption reduces oxidative DNA damage and plasma free radical levels in healthy Koreans. Mutat Res 2003;529:77-86.

21. Park YK, Lee SH, Park EJ et al. Changes in antioxidant status, blood pressure, and lymphocyte DNA damage from grape juice supplementation. Ann NY Acad Sci 2009;1171:385-90.

22. Vigna GB, Costantini F, Aldini G, et al. Effect of a standardized grape seed extract on low-density lipoprotein susceptibility to oxidation in heavy smokers. Metabolism 2003;52:1250-7.

23. Zern TL, Wood RJ, Greene C, et al. Grape polyphenols exert a cardioprotective effect in pre- and postmenopausal women by lowering plasma lipids and reducing oxidative stress. J Nutr 2005;135:1911-7.

24. Castilla P, Echarri R, Davalos A, et al. Concentrated red grape juice exerts antioxidant, hypolipidemic, and antiinflammatory effects in both hemodialysis patients and healthy subjects. Am J Clin Nutr 2006;84:252-62.

25. Kim MJ, Kim YJ, Parkh J, et al. Apoptic effect of red wine polyphenols on human colon cancer SNU-C4 cells. Food Chem Toxicol 2006;44:898-902. 
26. Sharif T, Auger C, Bronner C, et al. Selective proapoptic activity of polyphenols from red wine on teratocarcinoma cell, a model of cancer stemlike cell. Invest New Drugs 2011; 29:239-47.

27. Caridi A, De Bruno A, Piscopo A, et al. Study of the inheritability of the yeast trait "interaction with natural antioxidant activity of red wine" in four generations of Saccharomyces cerevisiae and its enhancing by spore clone selection and hybridization. Eur Food Res Technol 2015;240:1059-63.

28. Greenrod W, Stockley CS, Burcham P, et al. Moderate acute intake of de-alcoholised red wine, but not alcohol, is protective against radiation-induced DNA damage ex vivo -Results of a comparative in vivo intervention study in younger men. Mut Res 2005;591:290301.

29. Lecour S, Blackhurst D, Marais D, Opie L. Lowering the degree of alcohol in red wine does not alter its cardioprotective effect. J Mol Cell Cardiol 2006;40:9978.

30. Roos YH. Phase transitions in foods. Waltham, MA: Academic Press, Inc.; 1995.

31. Heldman DR, Hartel RW. Principles of Food Processing. New York, NY: Chapman \& Hall; 1997. pp 211-218.

32. Munin M, Edwards-Lévy F. Encapsulation of natural polyphenolic compounds; a Review. Pharmaceutics 2011;3:793-829.

33. Tonon RV, Brabet C, Hubinger MD. Anthocyanin stability andantioxidant activity of spray-dried açai (Euterpe oleracea Mart.) juice produced with different carrier agents. Food Res Int 2010;43:907-14.

34. Ferrari CC, Marconi Germer SP, Alvim ID, de Aguirre JM. Storage stability of spray-dried blackberry powder produced with maltodextrin or gum Arabic. Dry Technol 2013;31:470-8.

35. Galmarini MV, Schebor C, Zamora MC, Chirife J. The effect of trehalose, sucrose and maltodextrin addition on physicochemical and sensory aspects of freeze $\square$ dried strawberry puree. Int $\mathrm{J}$ Food Sci Tech 2009;44:1869-76.

36. van Galde $\mathrm{PH}$, van der Westelaken $\mathrm{M}$, Bruma BN, van de Weil. A Characteristics of piraltin, a polyphenol concentrate produced by freeze drying of red wine. Life Sci 2003;74:1159-66.

37. Sanchez V, Baeza R, Galmarini MV, et al. Freeze-drying encapsulation of red wine polyphenols in an amorphous matrix of maltodextrin. Food Bioproc Tech 2013;6:1350-4.
38. Galmarini MV, van Baren CM, Zamora MC, Chirife J. Trehalose as a drying aid of fruit products: Influence on physical properties, sensory characteristics and volatile retention. In: Rosana Filip, ed. Multidisciplinary Approaches on Food Science and Nutrition for the XXI Century 2010. Kerala, India: Transworld Research Network; [In press].

39. Adhikari B, Howes T, Bhandari B, Truong V. Surface stickiness of low molecular weight sugars and maltodextrin during drying. Food Ind $\mathrm{J}$ 2002;5:112-24.

40. Talja RA, Roos YH, Jouppila K. Glass transition behaviour of binary polyols mixtures. IFT Annual Meeting 2003. Chicago: Paper; 2003:60A-27.

41. Win KZ, Menon N. Glass transition of glycerol in the volume-temperature plane. Phys Rev E Stat Nonlin Soft Matter Phys 2006;73:040501.

42. Zondervan R, Kulzer F, Berkhout GCG, Orrit M. Local viscosity of supercooled glycerol near $\mathrm{Tg}$ probed by rotational diffusion of ensembles and single dye molecules. Proc Natl Acad Sci USA 2007;104:12628-33.

43. Rahman MS. Food properties handbook. 2nd ed. Boca Raton, FL: CRC press; 2009.

44. Bhandari BR, Roos YH. Non-equilibrium states and glass transitions in foods: processing effects and product-specific implications. Woodhead Publishing Series in Food Science, Technology and Nutrition; 2016.

45. Alvarez Gaona IJ, Bater C, Zamora MC, Chirife J. Spray drying encapsulation of red wine: Stability of total monomeric anthocyanins and structural alterations upon storage. J Food Process Pres 2017; e13457.

46. Galmarini MV, Maury C, Mehinagic E, et al. Stability of individual phenolic compounds and antioxidant activity during storage of a red wine powder. Food Bioprocess Tech 2013;6:3585-95.

47. Buera MP, Welti-Chanes J, Lillford P, Corti HR. Water properties of food, pharmaceutical and biological materials. Boca Raton, FL: CRC Press, Taylor \& Francis Group; 2006.

48. Rocha-Parra D, Galmarini MV, Chirife $\mathrm{J}$, Zamora MC. Influence of information, gender and emotional status for detecting small differences in the acceptance of a new healthy beverage. Food Res Int 2015;76:269-76.

49. Rocha-Parra D, García-Burgos D, Munsch S, et al. Application of hedonic dynamics using multiple-sip temporalliking and facial expression for evalua- tion of a new beverage. Food Qual Pref 2016;52:153-9.

50. Rocha-Parra DF. Desarrollo de una bebida en polvo conteniendo los polifenoles del vino tinto: caracterización fisicoquímica y sensorial. $\mathrm{PhD}$ dissertation. Universidad Nacional de La Plata, Buenos Aires, Argentina, 2016.

51. Kallithraka S, Salacha MI, Tzourou I. Changes in phenolic composition and antioxidant activity of white wine during bottle storage: Accelerated browning test versus bottle storage. Food Chem 2009;113:500-5.

52. Sun-Waterhouse D, Wadhwa SS, Waterhouse G. Spray-drying microencapsulation of polyphenol bioactives: a comparative study using different natural fibre polymers as encapsulants. Food Bioprocess Tech 2013;6:2376-88.

53. Sun-Waterhouse D, Waterhouse GI. Spray-drying of green or gold kiwifruit juice-milk mixtures; novel formulations and processes to retain natural fruit colour and antioxidants. Food Bioprocess Tech 2015;8:191-207.

54. Lu Z, Cheng B, Hu Y, Zhang Y, et al. Complexation of reservatrol with cyclodextrins: Solubility and antioxidant activity. Food Chem 2009;113:1720.

55. Mercader-Ros MT, Lucas-Abellán C, Fortea MI, et al. Effect of HP- $\beta$ cyclodextrins complexation on the antioxidant activity of flavonols. Food Chem 2010;118:769-73.

56. Fang Z, Bhandari B. Encapsulation of polyphenols-a review. Trends Food Sci Tech 2010;21:510-23.

57. Fang Z, Bhandari B. Comparing the efficiency of protein and maltodextrin on spray drying of bayberry juice. Food Res Int 2012;48:478-83.

58. Serrano-Cruz MR, Villanueva-Carvajal A, Rosales EJ M, et al. Controlled release and antioxidant activity of Roselle (Hibiscus sabdariffa L.) extract encapsulated in mixtures of carboxymethyl cellulose, whey protein, and pectin. LWT-Food Sci Technol 2013;50:554-61.

59. Pasrija D, Ezhilarasi PN, Indrani D, Anandharamakrishnan C. Microencapsulation of green tea polyphenols and its effect on incorporated bread quality. LWT-Food Sci Technol 2015;64:289-96.

60. Wilkowska A, Ambroziak W, Adamiec J, Czyżowska A. Preservation of antioxidant activity and polyphenols in chokeberry juice and wine with the use of microencapsulation. J Food Process Pres 2016;41:e12924.

61. Wilkowska A, Czyżowska A, 
Ambroziak W, Adamiec J. Structural, physicochemical and biological properties of spray-dried wine powders. Food Chem 2017;228:77-84.

62. Roos Y, Karel M. Phase transitions of mixtures of amorphous polysaccharides and sugars. Biotechnol Progr 1991;7:49-53.

63. Rankine BC, Bridson DA. Glycerol in Australian wines and factors influenc- ing its formation. Am J Enol Viticult 1971;22:6-12.

64. Avellone G, Salvo A, Costa R, et al. Investigation on the influence of spraydrying technology on the quality of Sicilian Nero d'Avola wines. Food Chem 2018;240:222-30.

65. Bomben JL, Bruin S, Merson RL. Aroma recovery and retention in concentration and drying of foods. Adv
Food Res 1973;20:1-111.

66. Menting LC, Hoogstad B. Volatiles retention during the drying of aqueous carbohydrate solutions. J Food Sci 1967;32:87-90.

67. Rulkens WH, Thijssen HAC. The retention of organic volatiles in spray-drying aqueous carbohydrate solutions. Int J Food Sci Technol 1972;7:95-105. 